\title{
Temperature, climate change, and birth weight: evidence from Hungary
}

\author{
Tamás Hajdu ${ }^{1}$. Gábor Hajdu²
}

Accepted: 9 March 2021 / Published online: 18 March 2021

(c) The Author(s) 2021

\begin{abstract}
We analyze the impact of in utero temperature exposure on the birth weight and an indicator for low birth weight using administrative data on singleton live births conceived between 2000 and 2016 in Hungary. We find that exposure to high temperatures during pregnancy decreases birth weight, but its impact on the probability of low birth weight is weaker. Exposure to one additional hot day (mean temperature $>25{ }^{\circ} \mathrm{C}$ ) during the gestation period reduces birth weight by $0.46 \mathrm{~g}$, relative to a 15-20 ${ }^{\circ} \mathrm{C}$ day. The second and third trimesters appear to be slightly more sensitive to temperature exposure than the first trimester. We project that climate change will decrease birth weight and increase the prevalence of low birth weight by the midtwenty-first century. The projected impacts are the strongest for newborns conceived during the winter and spring months.
\end{abstract}

Keywords Birth weight $\cdot$ Low birth weight $\cdot$ Health at birth $\cdot$ Temperature $\cdot$ Climate change

\section{Introduction}

Birth weight and other indicators of health at birth predict important outcomes in later life, including childhood, adolescent, and adult health, as well as educational attainment and labor market outcomes (Almond et al., 2018; Almond \& Currie, 2011; Behrman \& Rosenzweig, 2004; Bharadwaj et al., 2018; Black et al., 2007; Case et al., 2005; Currie, 2009, 2011; Figlio et al., 2014). Recognizing the importance of these indicators, a growing number of papers examine how different shocks in utero influence health at birth. These studies showed that environmental factors-among others air pollution, drinking water contamination, agricultural

Tamás Hajdu

hajdu.tamas@krtk.hu

1 Institute of Economics, Centre for Economic and Regional Studies, Tóth Kálmán u. 4, 1097 Budapest, Hungary

2 Institute for Sociology, Centre for Social Sciences, Tóth Kálmán u. 4, 1097 Budapest, Hungary 
fires, earthquakes, radiation, and toxic releases - are among the key determinants of health at birth (Coneus \& Spiess, 2012; Currie et al., 2013, 2014, 2015; Currie \& Schmieder, 2009; DeCicca \& Malak, 2020; Jones, 2020; Menclova \& Stillman, 2020; Pedersen et al., 2013; Quansah et al., 2015; Rangel \& Vogl, 2019; Torche, 2011; Tsou et al., 2019; Yang et al., 2003).

As the Earth's climate is projected to warm rapidly in the next decades (IPCC 2014, 2018), a notable research line focuses on the impact of in utero temperature exposure on birth weight (Andalón et al., 2016; Chen et al., 2020; Davenport et al., 2020; Deschênes et al., 2009; Grace et al., 2015; Molina \& Saldarriaga, 2017; Ngo \& Horton, 2016; Sun et al., 2019). These studies found that exposure to heat during pregnancy decreases birth weight and increases the probability of being born with low birth weight. However, the results regarding the impact of cold temperatures are mixed. Some studies have found that in utero exposure to cold temperatures increases birth weight (Deschênes et al., 2009). Others have found a negative (Ngo \& Horton, 2016; Sun et al., 2019) or zero impact (Andalón et al., 2016; Chen et al., 2020; Molina \& Saldarriaga, 2017). The results are also mixed in terms of which trimester is the most sensitive to temperature exposure.

A handful of papers examine the impacts of in utero exposure to other weather indicators on birth weight, e.g., sunshine (Trudeau et al., 2016; Zhang et al., 2020) or storms and hurricanes (Beuermann \& Pecha, 2020; Currie \& Rossin-Slater, 2013; Simeonova, 2011). Furthermore, other related literature analyzes the long-term impacts of in utero temperature exposure (Fishman et al., 2019; Hu \& Li, 2019; Isen et al., 2017; Wilde et al., 2017).

Despite the numerous studies on the relationship between in utero temperature exposure and birth weight, only two papers have dealt with the impacts of climate change. One of them quantified the impact of climate change using projections from a single climate model (Deschênes et al., 2009), by which it failed to account for the full extent of the uncertainty of future climate (Burke et al., 2015a, 2015b). The other one used predictions from 33 climate models (Ngo \& Horton, 2016), but even this study ignored regression uncertainty, which is, in this case, uncertainty in the historical relationship between temperature exposure and birth weight (Burke et al., 2015a, 2015b).

In this paper, we explore the impacts of in utero temperature exposure on birth weight and the probability of low birth weight. We use administrative data of the Hungarian Central Statistical Office that cover more than 1.5 million singleton live births conceived between 2000 and 2016 in Hungary. The effects of in utero temperature exposure are identified from year-to-year variation after controlling for countyspecific annual shocks and seasonality. We find that temperature exposure during pregnancy has a significant impact on birth weight, whereas its effect on the probability of low birth weight is weaker. In general, exposure to higher temperatures decreases birth weight, but the relationship seems to be nonlinear. Using historical estimates, we project the impact of climate change by the middle of the twenty-first century. Our calculations show that average birth weight will decrease, whereas the prevalence of low birth weight is likely to increase by 2040-2059. In addition, the projected impacts of climate change vary across births conceived in different parts of the year. 
Our paper contributes to the existing literature in several ways. We explore the impact of in utero temperature exposure in a Central European country. This region was missing from the literature until now. More importantly, this is one of few papers that project the impact of climate change on birth weight and low birth weight. In these calculations, we account for both climate and regression uncertainty and show the importance of this approach. Furthermore, for the first time in the literature, we also explore the impact of climate change across the calendar weeks of conception.

\section{Data}

\section{Live births}

Live birth data come from the administrative registers of the Hungarian Central Statistical Office. The birth records contain detailed information on the newborns and their parents. We have information on the exact birth date, sex, birth weight, and gestational age of the newborn babies, as well as on the level of education, employment, residence, and birth date of both the mother and the father, and on the pregnancy history and marital status of the mother. We consider two outcome variables: (1) birth weight (measured in grams) and (2) an indicator for low birth weight (LBW, birth weight $<2500 \mathrm{~g}$ ).

Information on the birth date and pregnancy length (reported in completed weeks) are used to estimate the beginning of the last menses. Next, based on the medical literature (Cole et al., 2009; Fehring et al., 2006; Lenton et al., 1984; Stirnemann et al., 2013), we assume that conception occurs on the 15th day of the menstrual cycle. Using the estimated conception dates, we define the conception year and the conception week of every live birth. ${ }^{1}$ For further details, see the Electronic Supplementary Materials.

We use data of singleton newborns conceived between 2000 and 2016. ${ }^{2}$ The county of a live birth record is defined by the place of residence of the mother (at the time of the birth). ${ }^{3}$ We excluded birth records with non-Hungarian or unknown places of residence, as well as births with missing information on pregnancy length or birth date (less than $1 \%$ of all singleton births in total). Our dataset covers $1,532,661$ singleton newborns.

\footnotetext{
${ }^{1}$ Each year is divided into 52 weeks, which means that the 52th week is 8 days long (9 days in leap years).

${ }^{2}$ By using a sample that is selected on the date of conception instead of the date of birth, we can avoid the bias that (for some conception weeks) pregnancies with a shorter gestation are missed at the start of the study period and pregnancies with a longer gestation are missed at the end (Strand et al., 2011).

${ }^{3}$ In accordance with the Nomenclature of Territorial Units for Statistics (NUTS) classification system, Budapest (the capital of Hungary) is considered an individual county; thus, we have 20 counties. Figure A1 (Electronic Supplementary Materials) displays the twenty counties of Hungary and the yearly average number of singleton births by county.
} 


\section{Weather data}

We use weather data from the E-OBS 19.0e dataset of the European Climate Assessment and Dataset project (Cornes et al., 2018), which provides daily weather measures for Europe. Using information on mean temperatures, eight weekly level temperature indicators are created that show the number of days in a given year-week and given county when the daily mean temperature falls in a certain temperature bin (below $-5{ }^{\circ} \mathrm{C},-5$ to $0{ }^{\circ} \mathrm{C}, 0$ to $5{ }^{\circ} \mathrm{C}, \ldots, 15$ to $20{ }^{\circ} \mathrm{C}, 20$ to $25^{\circ} \mathrm{C}$, over $25{ }^{\circ} \mathrm{C}$ ). ${ }^{4}$ In addition, we create four precipitation variables that indicate the number of days when the amount of daily precipitation falls in a certain precipitation bin $(0 \mathrm{~mm}, 0-1$ $\mathrm{mm}, 1-5 \mathrm{~mm}$, over $5 \mathrm{~mm}$ ). The temperature and precipitation variables are linked to the birth records by the county of residence of the mother.

The annual distribution of daily mean temperature by county is summarized in Table A1 (Electronic Supplementary Materials), whereas Fig. A2 (Electronic Supplementary Materials) shows the average temperature exposure for a 39-week-long pregnancy by conception week during 2000-2016. For further details, see the Electronic Supplementary Materials.

\section{Climate change projections}

We use projections of 21 climate models of the NASA Earth Exchange Global Daily Downscaled Projections (NEX-GDDP) dataset to calculate the impact of climate change by the mid-twenty-first century (2040-2059). The NEX-GDDP dataset provides daily maximum and minimum temperatures for 2006-2100 and retrospectively simulated temperatures for 1950-2005 (Thrasher et al., 2012). We use projected temperature changes under the representative concentration pathway scenario (RCP) 8.5, which represents a business-as-usual scenario (greenhouse gas emissions continue to rise in the twenty-first century) (Moss et al., 2010).

As for the historical weather data, we created eight temperature indicators to describe the temperature distributions in the periods of 2040-2059 and 1986-2005 by county and calendar week for each climate model. The mean temperature is calculated as the mean of the maximum and minimum temperatures. The period of 1986-2005 serves as a baseline, and the within-model changes in temperatures are calculated by differencing the temperature distributions (the eight temperature variables) between 2040-2059 and 1986-2005. To make a projection for the whole country, we average the county-level temperature changes. For this aggregation, we use the counties' average number of births conceived between 2000 and 2016 as weights. As a result, we have calendar-week-level temperature changes by climate models. For the calculation of the projected impacts of climate change, we use these country-level changes. For further details, see the Electronic Supplementary Materials.

\footnotetext{
${ }^{4}$ In Hungary, daily mean temperature of $25{ }^{\circ} \mathrm{C}$ is the threshold for first-level warning of extreme heat.
} 


\section{Methods}

\section{Historical relationship between temperature and birth weight}

We estimate the effect of in utero temperature exposure on birth weight as follows:

$$
Y_{i c t}=\sum_{j} \beta^{j} \sum_{a=0}^{38} T_{c(t+a)}^{j}+\sum_{k} \gamma^{k} \sum_{a=0}^{38} P_{c(t+a)}^{k}+\tau X_{i c t}+\mu_{c y}+\rho_{c w}+\varepsilon_{i c t}
$$

where $Y$ is the birth weight or an indicator for LBW of newborn $i$ conceived at time $t$ (conception year $y$, conception week $w$ ) in county $c . T$ is a vector of weekly level temperature variables that shows the number of days in temperature category $j$ (below $-5{ }^{\circ} \mathrm{C},-5-0{ }^{\circ} \mathrm{C}, 0-5{ }^{\circ} \mathrm{C}, 5-10{ }^{\circ} \mathrm{C}, 10-15{ }^{\circ} \mathrm{C}, 15-20{ }^{\circ} \mathrm{C}, 20-25{ }^{\circ} \mathrm{C}$, or above $25^{\circ} \mathrm{C}$ ). The temperature variables entered in the regression show the temperature exposure during the entire pregnancy, assuming a 39-week-long gestation period (started with the week of conception). In this analysis, the number of days with a mean temperature of $15-20{ }^{\circ} \mathrm{C}$ is the omitted category. That is, coefficient $\beta^{j}$ shows the effect of one additional day during a 39-week-long gestation period when the daily mean temperature falls into temperature bin $j$ on birth weight/LBW (relative to a day with a mean temperature of $15-20^{\circ} \mathrm{C}$ ). We use temperature exposure during a 39-week-long gestation period rather than temperature exposure during the observed average gestation length, as there is a mechanical correlation between pregnancy length and the number of days when the daily mean temperature falls into different temperature bins. This approach is frequently used in the empirical in utero exposure literature (Chen et al., 2020; Currie \& Rossin-Slater, 2013; Deschênes et al., 2009). The descriptive statistics of the dependent and main right-hand-side variables are shown in Table 1, whereas Table A2 (Electronic Supplementary Materials) summarizes the descriptive statistics of the control variables.

$P$ is a vector of precipitation controls, which shows the number of days where the amount of daily precipitation falls in precipitation bin $k(0 \mathrm{~mm}, 0-1 \mathrm{~mm}, 1-5 \mathrm{~mm}$, over 5 $\mathrm{mm}) . X$ is a vector of the observable characteristics of the parents and births and includes the education of the mother, her employment status, her age, her marital status, and her history of pregnancies (number of previous pregnancies, live births, and abortions). We control for education, age, and employment of the father and sex of the newborns. All of these characteristics are captured by categorical variables. Some of these control variables directly influence health at birth, whereas most of them are related to other important factors (e.g., diet, smoking, stress, maternal health, access to medical care) that are unobserved in the administrative data we use but shape health at birth (Aizer \& Currie, 2014; Currie, 2011); thus, they could improve the precision of the estimations. In addition, they might help to partially control the fact that in utero temperature exposure changes the composition of fetuses that survive to live birth (Basu et al., 2016; Davenport et al., 2020; Ha et al., 2017; Hajdu \& Hajdu, 2021; Li et al., 2018; Rammah et al., 2019; Strand et al., 2012), often called the "culling" effect. As in utero selection due to an adverse event is likely to remove male fetuses and fetuses with below-average health, the impacts of a fetal health shock are underestimated (Almond \& Currie, 2011; Bruckner \& Catalano, 2018; 
Table 1 Descriptive statistics

\begin{tabular}{llllll}
\hline Variable & Mean & SD & Min & Max & $N$ \\
\hline Birth weight & 3287.7 & 557.5 & 301 & 6499 & $1,532,661$ \\
LBW & 0.067 & 0.251 & 0 & 1 & $1,532,661$ \\
Temperature exposure & & & & & \\
$\quad \begin{array}{l}\text { during pregnancy (in } \\
\text { days) }\end{array}$ & & & & & \\
$\quad$ Below $-5^{\circ} \mathrm{C}$ & 7.9 & 7.6 & 0 & 36.4 & $1,532,661$ \\
$\quad 5$ to $0{ }^{\circ} \mathrm{C}$ & 24.1 & 14.0 & 0 & 64.7 & $1,532,661$ \\
$\quad 0$ to $5{ }^{\circ} \mathrm{C}$ & 41.3 & 15.8 & 0 & 75.0 & $1,532,661$ \\
5 to $10{ }^{\circ} \mathrm{C}$ & 45.6 & 16.1 & 9.9 & 90.8 & $1,532,661$ \\
10 to $15^{\circ} \mathrm{C}$ & 46.5 & 13.4 & 8.3 & 82.7 & $1,532,661$ \\
15 to $20^{\circ} \mathrm{C}$ & 54.1 & 17.4 & 13.6 & 99.8 & $1,532,661$ \\
20 to $25{ }^{\circ} \mathrm{C}$ & 42.9 & 18.5 & 0.9 & 84.2 & $1,532,661$ \\
$\quad$ Above $25^{\circ} \mathrm{C}$ & 11.6 & 9.0 & 0 & 40.3 & $1,532,661$ \\
\hline
\end{tabular}

The in utero exposure period is defined as a 39 -week-long period starting with the week of conception

Catalano et al., 2012). We aim to estimate the "scarring" effect of in utero temperature exposure on birth weight (and not only the effect on "survivors"); therefore, the culling effect should be controlled for as much as possible. Although we cannot completely rule out its influence, by including the sex of the newborn and the characteristics of the parents, we might capture some of the impacts of in utero selection (although the extent is unclear), as changes in the observed characteristics are controlled for.

Time-invariant seasonal differences in average birth weight and prevalence of low birth weight across counties are captured by county-by-calendar-week fixed effects $\left(\rho_{\mathrm{cw}}\right)$. County-by-year fixed effects $\left(\mu_{\mathrm{cy}}\right)$ control for county-specific shocks in a given conception year. In sum, we exploit the year-to-year variation in the calendar-weekspecific in utero temperature exposure. The effect of temperature is identified from this interannual temperature variation after adjusting for differences in county-specific seasonality and county-specific shocks to health at birth at the year level.

We also examine the impact of temperature exposure by trimesters. Trimester 1 is defined as the first 13 weeks of the gestation period (including the conception week), whereas weeks 14-26 and weeks 27-39 are assigned to trimesters 2 and 3, respectively:

$$
\begin{aligned}
Y_{i c t}= & \sum_{j} \beta^{1 j} \sum_{a=0}^{12} T_{c(t+a)}^{1 j}+\sum_{j} \beta^{2 j} \sum_{a=13}^{25} T_{c(t+a)}^{2 j} \\
& +\sum_{j} \beta^{3 j} \sum_{a=26}^{38} T_{c(t+a)}^{j}+\sum_{k} \gamma^{1 k} \sum_{a=0}^{12} P_{c(t+a)}^{1 k} \\
& +\sum_{k} \gamma^{2 k} \sum_{a=13}^{25} P_{c(t+a)}^{2 k}+\sum_{k} \gamma^{3 k} \sum_{a=26}^{38} P_{c(t+a)}^{3 k} \\
& +\tau X_{i c t}+\mu_{c y}+\rho_{c w}+\varepsilon_{i c t}
\end{aligned}
$$


From this estimation, we can infer which pregnancy period is the most sensitive to temperature exposure.

Standard errors are clustered by county and conception year $\times$ conception week (two-way clustering). For the estimations, we use STATA package reghdfe (Correia, 2014).

\section{Projected impacts of climate change}

The impacts of climate change are quantified by combining the estimates of the effect of in utero temperature exposure on birth weight/LBW with the projected within-model changes in temperature distribution between the periods of 1986-2005 and 2040-2059. Specifically, we take $\beta$ coefficients from Eq. 1 and multiply them by the projected temperature changes, assuming a 39-week-long pregnancy period:

$$
\Delta Y_{m w}=\sum_{j} \beta^{j} \sum_{a=0}^{38} \Delta T_{m(w+a)}^{j}
$$

where $m$ denotes the climate model and $w$ denotes calendar week. $\Delta Y$ is the projected change in birth weight or prevalence of LBW for live births started in calendar week $w . \beta^{j}$ is the estimated relationship between temperature category $j$ and the birth weight or prevalence of LBW (from Eq. 1). $\Delta T$ is a vector that shows the projected change in weekly temperature distribution between 1986-2005 and 2040-2059 for calendar week $w$ and climate model $m$. That is, the results of this calculation are the projected impact of climate change by the calendar week of conception.

The average (overall) impact of climate change is calculated by averaging the projected calendar-week-level impacts. For this calculation, we use a weight (denoted by $f$; scaled to mean 1 ) based on the calendar weeks' average number of live births in our sample:

$$
\Delta Y_{m}=\sum_{w} \frac{f_{w} \Delta Y_{m w}}{52}
$$

We use projections from 21 climate models to account for climate uncertainty. Furthermore, we account for uncertainty in the historical relationship between temperature exposure and birth weight/LBW by bootstrapping the coefficient estimates of Eq. 1 (1000 times, sampling with replacement). ${ }^{5}$ Using the coefficients from the 1000 estimations and the projections of the 21 climate models, we construct 21,000 possible projections of the impact of climate change (1000 projections by climate

\footnotetext{
${ }^{5}$ In each estimation, a random sample is taken from the $1,532,661$ observations by using sampling with replacement. The new sample, as the original data, has a sample size of 1,532,661, but a given newborn can be selected more than once. Next, we estimate Eq. (1) on this new sample. The sampling process and the estimation are repeated by 1000 times. As a result, we have 1000 coefficients for each temperature category that incorporate the uncertainty in the historical relationship between temperature exposure and birth weight/LBW.
} 
model) by which we can incorporate both climate and regression uncertainty into the projected impacts of climate change (Burke, Dykema et al., 2015a, 2015b).

In these calculations, we assume that the future relationship between temperature and birth weight/LBW will be the same as in the past. We cannot rule out that future adaptation might change the observed temperature-birth weight/LBW relationship. However, credible empirical estimates are missing regarding a possible future adaptation process. In addition, projecting impacts in the absence of future adaptation is a standard approach in the empirical literature on the impacts of climate change (Barreca \& Schaller, 2020; Burke et al., 2018; Burke, Hsiang, et al., 2015a, 2015b; Deschênes et al., 2009; Obradovich et al., 2017).

\section{Results}

\section{Impact of in utero temperature exposure}

Figure 1 summarizes the impact of in utero temperature exposure on birth weight (panel "a") and low birth weight (panel "b"). We find that temperature exposure during pregnancy has a significant influence on birth weight. Exposure to one additional $>25^{\circ} \mathrm{C}$ day in utero, relative to a day with a mean temperature of $15-20{ }^{\circ} \mathrm{C}$, reduces birth weight by $0.46 \mathrm{~g}(95 \% \mathrm{CI}-0.71$ to $-0.21, p=0.001)$. The effect of exposure to an additional $20-25{ }^{\circ} \mathrm{C}$ day is also negative but slightly lower in magnitude: $-0.36 \mathrm{~g}(95 \% \mathrm{CI}-0.54$ to $-0.17, p=0.001)$. Colder temperatures below the omitted category $\left(15-20{ }^{\circ} \mathrm{C}\right.$ ) seem to have small positive effects; however, all the 95\% confidence intervals include zero. Thus, our findings suggest that temperature has a nonlinear effect on birth weight.
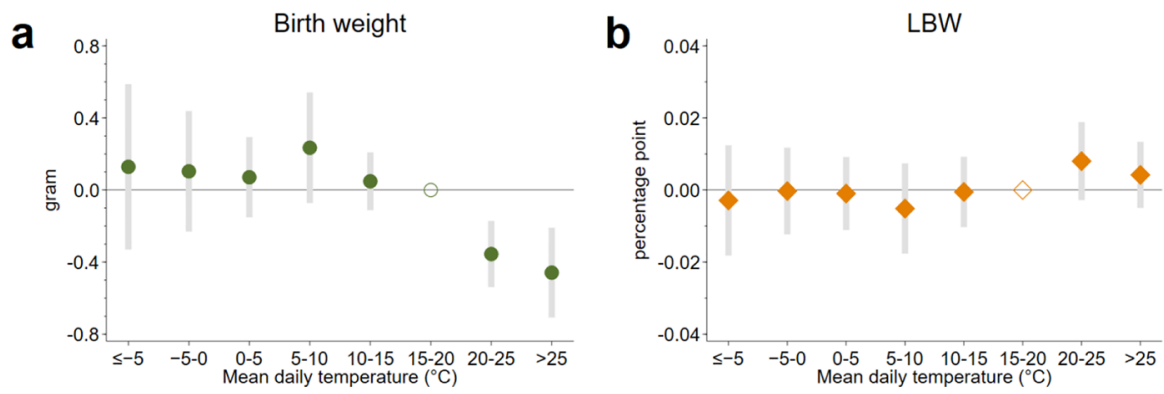

Fig. 1 Effect of in utero temperature exposure on birth weight/LBW. The effect of in utero exposure to one additional day with different mean temperatures on birth weight (a) and LBW (b) relative to a day with a mean temperature of $15-20{ }^{\circ} \mathrm{C}$. The circles/diamonds are the point estimates, and the error bars represent $95 \%$ confidence intervals. The estimations come from Eq. 1. The model has county-by-year fixed effects and county-by-calendar-week fixed effects. Precipitation, sex of the newborns, and the characteristics of the parents (age, education, employment, marital status of the mother, pregnancy history of the mother) are controlled for. The in utero exposure period is defined as a 39-week-long period starting with the week of conception. Standard errors are clustered by county and time (conception year $\times$ conception week). $N=1,532,661$ 
Regarding the impacts on low birth weight, we find no significant effects. ${ }^{6} \mathrm{Nev}-$ ertheless, the estimated impacts are in line with the harmful effect of exposure to heat. The point estimates for temperature categories above the reference category are positive, whereas they are negative for colder temperature bins below the reference category. However, as prenatal selection is likely to remove "weaker" fetuses, the estimations using LBW as dependent variable (a direct indicator of "weaker" newborns) might be more strongly influenced by the culling effect.

The sensitivity of the results is tested by additional model specifications: excluding live births with less than 26 weeks of gestation, including county-by-calendarweek-specific quadratic time trends, using less restrictive fixed effects, and adding municipality of residence fixed effects. Models without the control variables and including gestation length are estimated as well. We also use log birth weight as a dependent variable. The results of these estimations for the two outcome variables are summarized separately in Tables A3 and A4 (Electronic Supplementary Materials). We also apply alternative clustering of the standard errors (Tables A5 and A6, Electronic Supplementary Materials). None of the changes alter the main conclusion. In general, the alternative specifications give similar results to the baseline estimations. Importantly, the specification including gestational length as an additional control variable indicates that newborns exposed to hot temperatures are likely to have slower intrauterine growth rather than shorter pregnancy. ${ }^{7}$

It might be interesting to note that the estimated temperature effects alone cannot explain the observed seasonal patterns of birth weight and LBW. In fact, differences in temperature exposure across the conception weeks would result in larger seasonal differences (Fig. A3, Electronic Supplementary Materials). If health at birth would be influenced only by in utero exposure to temperatures, the newborns conceived between July and October should have higher birth weight and lower LBW rate than newborns conceived in the first half of the year and the last few weeks. In contrast, the observed seasonal patterns are remarkably different. These results are not very surprising since many factors play a role in shaping seasonal differences in birth weight. For example, the pregnancies starting between July and October are exposed to the elevated air pollution of the autumn and winter months (e.g., due to solid fuel heating) (Bodor et al., 2020; Cichowicz et al., 2017), which might lower their health at birth (Currie et al., 2014; Pedersen et al., 2013). Exposure to sunshine, influenza, or other seasonal pandemics also vary depending on the conception week, therefore could contribute to the observed seasonal pattern of birth weight (Azziz Baumgartner et al., 2012; Nunes et al., 2016; Rasmussen et al., 2012; Trudeau et al., 2016; Zhang et al., 2020).

Next, we estimate the impacts of in utero temperature exposure by trimester. These estimations come from Eq. 2 and are summarized in Fig. 2. In general, these

\footnotetext{
${ }^{6}$ However, as prenatal selection is likely to remove "weaker" fetuses, the estimations using LBW as dependent variable (a direct indicator of "weaker" newborns) might be more strongly influenced by the culling effect.

7 No significant and substantial differences are observed estimating the baseline specification for newborns of high or low educated mothers (Fig. A5, Electronic Supplementary Materials), or newborns in counties with higher or lower yearly average temperature (Fig. A6, Electronic Supplementary Materials).
} 

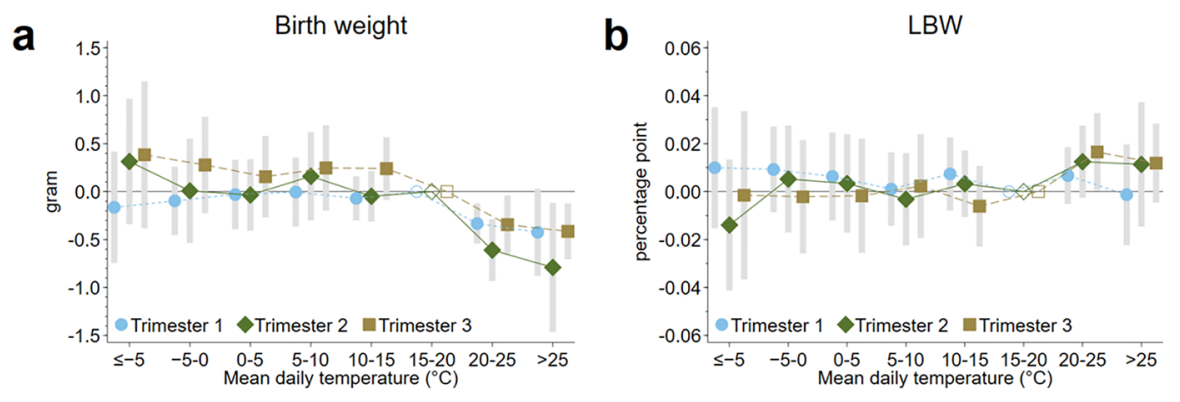

Fig. 2 Effect of in utero temperature exposure by trimester. The effect of in utero exposure to one additional day with different mean temperatures on birth weight $\mathbf{a}$ and LBW $\mathbf{b}$ relative to a day with a mean temperature of $15-20{ }^{\circ} \mathrm{C}$. The circles/diamonds/squares are the point estimates, and the error bars represent $95 \%$ confidence intervals. The estimations come from Eq. 2. The model has county-by-year fixed effects and county-by-calendar-week fixed effects. Precipitation, sex of the newborns, and the characteristics of the parents (age, education, employment, marital status of the mother, pregnancy history of the mother) are controlled for. The in utero exposure period is defined as a 39-week-long period starting with the week of conception. Standard errors are clustered by county and time (conception year $\times$ conception week). $\mathrm{N}=1,532,661$

estimations show large uncertainty, which is indicated by the large standard errors. The coefficients are not different from each other across trimesters. Nevertheless, temperature exposure may have a weaker impact during the first trimester than during the second and third trimesters. It is especially apparent for LBW; however, even for birth weight, the impacts of cold and hot temperatures are less different in the first trimester.

As a placebo test, we estimate Eq. 1 with exposure to temperature in the future instead of exposure to temperature during the actual gestation period. Specifically, the exposure variables (temperature and precipitation) are replaced with weather data that were measured exactly one year later. Since the birth weight of the newborns could not have been affected by temperature exposure 1 year after conception (that is, several months after the birth), insignificant and close to zero coefficients are expected in these placebo regressions if our model is correctly specified. In general, the estimated impacts are substantially different from the baseline results (Fig. A4, Electronic Supplementary Materials). Importantly, we do not observe similar patterns as in Fig. 1. The estimated impacts show fairly random patterns, and positive and negative point estimates can be found both below and above the reference category. We can conclude that temperature 1 year later does not have any impact on birth weight or LBW. In sum, these estimations support the credibility of the baseline results.

\section{Impacts of climate change}

Figure 3 depicts the projected impacts of climate change on birth weight and prevalence of LBW by the mid-twenty-first century from Eq. 4. We present medians, interquartile 


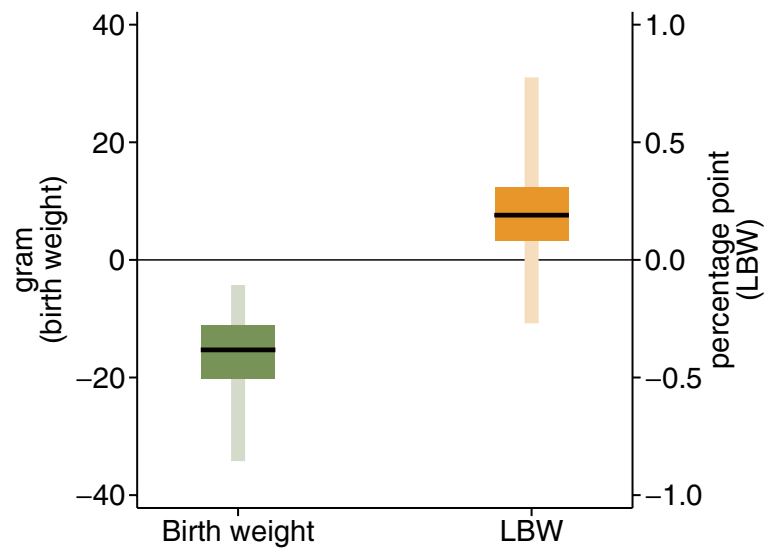

Fig. 3 Projected impacts of climate change by the mid-twenty-first century. Impacts of climate change by 2040-2059 on birth weight and prevalence of low birth weight. The impacts are calculated using (i) the projected within-model differences in the temperature distribution between the periods of 1986-2005 and 2040-2059 by 21 climate models under RCP 8.5 and (ii) the historical relationship between in utero temperature exposure and birth weight/LBW from Eq. 1 (estimated by 1000 bootstrap samples). The black lines show the median projections. The dark shaded areas show the interquartile range of the projections. The hollow shaded bars represent the range containing $99 \%$ of the projections. The projected impacts for birth weight are shown on the left horizontal axis. The projected impacts for LBW are shown on the right horizontal axis

ranges, and the ranges containing $99 \%$ of the projections. ${ }^{8}$ For birth weight, the projections suggest a sizeable decline. The median projection is $-15.3 \mathrm{~g}$. The interquartile range of the projections spreads from -20.2 to $-11.2 \mathrm{~g}$. The upper bound of the ranges containing $99 \%$ of the projections is $-34.2 \mathrm{~g}$, whereas the lower bound is $-4.3 \mathrm{~g}$.

For LBW, some of the projections predict a decrease by 2040-2059, but most of them project an increased prevalence of LBW. The median projection is an increase of 0.19 percentage points. The interquartile range spread from 0.08 to 0.31 percentage points, whereas some projections are as high as 0.78 percentage points. The lower bound of the ranges containing $99 \%$ of the projections is -0.27 percentage points. These are nonnegligible changes considering that $6.7 \%$ of the singleton newborns were born with low birth weight in our sample, which means that the interquartile range represents an increase of $1.3-4.6 \%$.

The projected impacts vary considerably across climate models. Figure A7 (Electronic Supplementary Materials) shows that projecting the impacts of climate change separately by the 21 climate models results in a wide range of projections. For example, the median projections regarding the impact on birth weight range between -25.7 and $-8.5 \mathrm{~g}$, whereas for LBW, they range between 0.11 and 0.33 percentage points. These differences stress the importance of accounting for climate uncertainty (Burke et al., 2015a, 2015b). However, accounting only for climate uncertainty might also lead to false certainty regarding the possible impacts of climate change. In Fig. A8

\footnotetext{
8 We took the 0.5 th and 99.5 th percentiles to calculate the ranges containing $99 \%$ of the projections.
} 

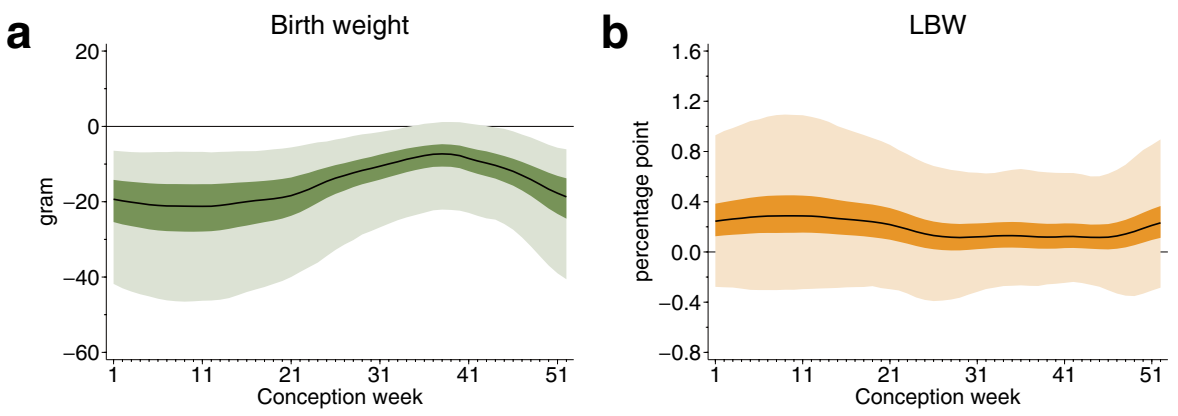

Fig. 4 Projected impacts of climate change by conception week of the year. Impacts of climate change by 2040-2059 on birth weight $\mathbf{a}$ and prevalence of low birth weight $\mathbf{b}$ by the week of conception. The impacts are calculated using (i) the projected within-model differences in the temperature distribution between the periods of 1986-2005 and 2040-2059 by 21 climate models under RCP 8.5 and (ii) the historical relationship between in utero temperature exposure and birth weight/LBW from Eq. 1 (estimated by 1000 bootstrap samples). The black lines show the median projections. The dark shaded areas show the interquartile range of the projections. The hollow shaded areas represent the range containing $99 \%$ of the projections

(Electronic Supplementary Materials), we show projections where regression uncertainty is excluded by using the coefficients from the baseline estimation (depicted in Fig. 1). The ranges containing $99 \%$ of the projections are much narrower in this case, which might be positive from a certain analytic point of view (higher degree of precision), but these projections would serve as misleading inputs for climate policy. In sum, credible projections on the impact of climate change require accounting for both climate and regression uncertainty.

Next, we investigate the impact of climate change-induced temperature changes by the calendar week of conception (Fig. 4). These calculations are based on Eq. 3 . The results of these exercises suggest that although the impacts on births conceived in different parts of the year are all negative, the magnitudes are somewhat different. The impacts are projected to be more severe for births conceived during the winter and spring months. For example, the largest impacts are projected for calendar week 11: the median projection in terms of the impact on birth weight is $-21.2 \mathrm{~g}$, whereas the interquartile range spreads between -27.9 and $-15.3 \mathrm{~g}$. In contrast, the median projection for calendar week 38 is $-7.3 \mathrm{~g}$ and the interquartile range is -10.7 to $-4.7 \mathrm{~g}$, an almost three-fold difference. For LBW, we observe similar differences but that are lower in magnitude. However, we note that the $99 \%$ ranges of the projections overlap for all calendar weeks. Nevertheless, these projections indicate that there is a nonnegligible difference in the severity of impacts of climate change across conception weeks.

\section{Discussion and conclusion}

In this paper, we studied the effect of in utero temperature exposure on birth weight and the prevalence of low birth weight. We used administrative data that covers more than 1.5 million singleton live births conceived between 2000 and 
2016 in Hungary. We showed that exposure to one additional day with a mean temperature $>25{ }^{\circ} \mathrm{C}$ reduces birth weight by $0.46 \mathrm{~g}$, whereas the impact of a $20-25{ }^{\circ} \mathrm{C}$ day is $-0.36 \mathrm{~g}$. Colder temperatures below the omitted category $(15-20$ ${ }^{\circ} \mathrm{C}$ ) seem to have rather positive, but small and statistically insignificant effects on birth weight. The impacts of temperature exposure on the probability of low birth weight are more modest.

As previous papers examined different countries that might have different climatic conditions, therefore, the comparison of our estimations with these studies is not straightforward. Nevertheless, our finding of a negative impact of exposure to hot temperatures is in line with the results of previous research (Chen et al., 2020; Davenport et al., 2020; Deschênes et al., 2009; Grace et al., 2015; Molina \& Saldarriaga, 2017; Sun et al., 2019). Regarding the impact of cold temperature, the results of the previous papers have been inconsistent. Although the results are mixed in terms of the sign of the impact, almost every study found that the impacts of cold temperatures are weaker (in absolute terms) than the impacts of hot temperatures, relative to a mild temperature (Chen et al., 2020; Deschênes et al., 2009; Molina \& Saldarriaga, 2017; Sun et al., 2019). Importantly, weaker impacts of in utero temperature exposure on LBW have been usually found in the related research (Andalón et al., 2016; Davenport et al., 2020; Molina \& Saldarriaga, 2017; Ngo \& Horton, 2016).

We also projected the impacts of climate change by the mid-twenty-first century (2040-2059). We showed that the average birth weight is likely to decrease due to climate change in Hungary, whereas we project an increase in the prevalence of low birth weight. Accounting for both climate and regression uncertainty, the interquartile ranges of the projections spread from -20.2 to $-11.2 \mathrm{~g}$ for birth weight, and from 0.08 to 0.31 percentage points (or 1.3-4.6\%) for LBW. We also showed that the impacts of climate change vary across births conceived in different parts of the year. Births conceived during the winter and spring months are projected to be affected more severely.

To put the magnitude of the projected impacts of climate change into context, we note that workplace smoking bans increase the birth weight of the most affected newborns by 50-60 g (Bharadwaj et al., 2014; Hajdu \& Hajdu, 2018). A recent study shows that a 1000 dollar increase in annual family income from the minimum wage increases birth weight by $4 \mathrm{~g}$ in the USA, while it has no effect on LBW (Wehby et al., 2020). The Women, Infants, and Children (WIC) program is reported to increase the birth weight of the participants' newborns by 20-60 g (Bitler \& Currie, 2005; Hoynes et al., 2011), while the estimated impacts on LBW are mixed (Bitler \& Currie, 2005; Currie \& Rajani, 2015; Hoynes et al., 2011). An Uruguayan social assistance program that targeted the poorest and increased household income by $25 \%$ is reported to decrease LBW by $20 \%$ and increase birth weight by $30 \mathrm{~g}$ (Amarante et al., 2016). The Food Stamp Program (FSP) increased birth weight by $15-40 \mathrm{~g}$ and decreased LBW by approximately 8\% (Almond et al., 2011).

Finally, as discussed earlier, in utero temperature exposure is likely to cause in utero selection that removes fetuses with below-average health (Almond \& Currie, 2011; Bruckner \& Catalano, 2018; Catalano et al., 2012). Therefore, our estimates 
do not simply reflect the scarring effect of temperature exposure but are influenced by this selection. As the bias stemming from prenatal selection cannot be completely controlled, our estimates can be considered as a lower bound of the true scarring effect of temperature exposure. As most fetal losses occur during the early period of pregnancy, even before clinical recognition (Jarvis, 2016; Wilcox et al., 2020), the first trimester estimates are more likely to be affected by selection-induced bias.

Supplementary information The online version contains supplementary material available at https://doi. org/10.1007/s11111-021-00380-y.

Acknowledgements We acknowledge climate scenarios from the NEX-GDDP dataset, prepared by the Climate Analytics Group and NASA Ames Research Center using the NASA Earth Exchange, and distributed by the NASA Center for Climate Simulation (NCCS). We acknowledge the E-OBS dataset from the EU-FP6 project UERRA (http://www.uerra.eu) and the Copernicus Climate Change Service, and the data providers in the ECA\&D project (https://www.ecad.eu). The present study has been produced using the live birth register of the Hungarian Central Statistical Office (HCSO). We accessed the de-identified dataset in the secure data environment of the HCSO after an accreditation process. The calculations and conclusions are the intellectual product of the authors.

Author contribution T.H. and G.H. designed the research and wrote the paper. T.H. analyzed the data.

Funding Open access funding provided by ELKH Centre for Economic and Regional Studies. This work was supported by the Hungarian National Research, Development and Innovation Office - NKFIH (grant no. FK 124310). Tamás Hajdu was also supported by the "Lendület" program of the Hungarian Academy of Sciences (grant no. LP2018-2/2018) and the János Bolyai Research Scholarship of the Hungarian Academy of Sciences.

\section{Declarations}

Competing interests The authors declare that they have no competing interests.

Disclaimer The sources of funding had no role in study design; in the collection, analysis, and interpretation of data; in the writing of the article; and in the decision to submit it for publication.

Open Access This article is licensed under a Creative Commons Attribution 4.0 International License, which permits use, sharing, adaptation, distribution and reproduction in any medium or format, as long as you give appropriate credit to the original author(s) and the source, provide a link to the Creative Commons licence, and indicate if changes were made. The images or other third party material in this article are included in the article's Creative Commons licence, unless indicated otherwise in a credit line to the material. If material is not included in the article's Creative Commons licence and your intended use is not permitted by statutory regulation or exceeds the permitted use, you will need to obtain permission directly from the copyright holder. To view a copy of this licence, visit http://creativecommons.org/ licenses/by/4.0/.

\section{References}

Aizer, A., \& Currie, J. (2014). The intergenerational transmission of inequality: Maternal disadvantage and health at birth. Science, 344(6186), 856-861. https://doi.org/10.1126/science.1251872

Almond, D., \& Currie, J. (2011). Killing me softly: The fetal origins hypothesis. Journal of Economic Perspectives, 25(3), 153-172. https://doi.org/10.1257/jep.25.3.153 
Almond, D., Currie, J., \& Duque, V. (2018). Childhood circumstances and adult outcomes: Act II. Journal of Economic Literature, 56(4), 1360-1446. https://doi.org/10.1257/jel.20171164

Almond, D., Hoynes, H. W., \& Schanzenbach, D. W. (2011). Inside the war on poverty: The impact of food stamps on birth outcomes. Review of Economics and Statistics, 93(2), 387-403. https://doi. org/10.1162/REST_a_00089

Amarante, V., Manacorda, M., Miguel, E., \& Vigorito, A. (2016). Do cash transfers improve birth outcomes? Evidence from matched vital statistics, program, and social security data. American Economic Journal: Economic Policy, 8(2), 1-43. https://doi.org/10.1257/pol.20140344

Andalón, M., Azevedo, J. P., Rodríguez-Castelán, C., Sanfelice, V., \& Valderrama-González, D. (2016). Weather shocks and health at birth in Colombia. World Development, 82, 69-82. https://doi. org/10.1016/j.worlddev.2016.01.015

Azziz Baumgartner, E., Dao, C. N., Nasreen, S., Bhuiyan, M. U., Mah-E-Muneer, S., Mamun, A. A., et al. (2012). Seasonality, timing, and climate drivers of influenza activity worldwide. The Journal of Infectious Diseases, 206(6), 838-846. https://doi.org/10.1093/infdis/jis467

Barreca, A., \& Schaller, J. (2020). The impact of high ambient temperatures on delivery timing and gestational lengths. Nature Climate Change, 10(1), 77-82. https://doi.org/10.1038/s41558-019-0632-4

Basu, R., Sarovar, V., \& Malig, B. J. (2016). Association between high ambient temperature and risk of stillbirth in California. American Journal of Epidemiology, 183(10), 894-901. https://doi. org/10.1093/aje/kwv295

Behrman, J. R., \& Rosenzweig, M. R. (2004). Returns to birthweight. The Review of Economics and Statistics, 86(2), 586-601. https://doi.org/10.1162/003465304323031139

Beuermann, D. W., \& Pecha, C. J. (2020). The effects of weather shocks on early childhood development: Evidence from 25 years of tropical storms in Jamaica. Economics \& Human Biology, 37, 100851. https://doi.org/10.1016/j.ehb.2020.100851

Bharadwaj, P., Johnsen, J. V., \& Løken, K. V. (2014). Smoking bans, maternal smoking and birth outcomes. Journal of Public Economics, 115, 72-93. https://doi.org/10.1016/j.jpubeco.2014.04.008

Bharadwaj, P., Lundborg, P., \& Rooth, D.-O. (2018). Birth weight in the long run. Journal of Human Resources, 53(1), 189-231. https://doi.org/10.3368/jhr.53.1.0715-7235R

Bitler, M. P., \& Currie, J. (2005). Does WIC work? The effects of WIC on pregnancy and birth outcomes. Journal of Policy Analysis and Management, 24(1), 73-91. https://doi.org/10.1002/pam.20070

Black, S. E., Devereux, P. J., \& Salvanes, K. G. (2007). From the cradle to the labor market? The effect of birth weight on adult outcomes. The Quarterly Journal of Economics, 122(1), 409-439. https://doi. org/10.1162/qjec.122.1.409

Bodor, Z., Bodor, K., Keresztesi, Á., \& Szép, R. (2020). Major air pollutants seasonal variation analysis and long-range transport of PM10 in an urban environment with specific climate condition in Transylvania (Romania). Environmental Science and Pollution Research, 27(30), 38181-38199. https:// doi.org/10.1007/s11356-020-09838-2

Bruckner, T. A., \& Catalano, R. (2018). Selection in utero and population health: Theory and typology of research. SSM - Population Health, 5, 101-113. https://doi.org/10.1016/j.ssmph.2018.05.010

Burke, M., Dykema, J., Lobell, D. B., Miguel, E., \& Satyanath, S. (2015a). Incorporating climate uncertainty into estimates of climate change impacts. The Review of Economics and Statistics, 97(2), 461-471. https://doi.org/10.1162/REST_a_00478

Burke, M., González, F., Baylis, P., Heft-Neal, S., Baysan, C., Basu, S., \& Hsiang, S. (2018). Higher temperatures increase suicide rates in the United States and Mexico. Nature Climate Change, 8(8), 723-729. https://doi.org/10.1038/s41558-018-0222-x

Burke, M., Hsiang, S. M., \& Miguel, E. (2015b). Global non-linear effect of temperature on economic production. Nature, 527(7577), 235-239. https://doi.org/10.1038/nature15725

Case, A., Fertig, A., \& Paxson, C. (2005). The lasting impact of childhood health and circumstance. Journal of Health Economics, 24(2), 365-389. https://doi.org/10.1016/j.jhealeco.2004.09.008

Catalano, R., Goodman, J., Margerison-Zilko, C. E., Saxton, K. B., Anderson, E., \& Epstein, M. (2012). Selection against small males in utero: a test of the Wells hypothesis. Human Reproduction, 27(4), 1202-1208. https://doi.org/10.1093/humrep/der480

Chen, X., Tan, C. M., Zhang, X., \& Zhang, X. (2020). The effects of prenatal exposure to temperature extremes on birth outcomes: the case of China. Journal of Population Economics. https://doi. org/10.1007/s00148-020-00768-4

Cichowicz, R., Wielgosiński, G., \& Fetter, W. (2017). Dispersion of atmospheric air pollution in summer and winter season. Environmental Monitoring and Assessment, 189(12), 605. https://doi. org/10.1007/s10661-017-6319-2 
Cole, L. A., Ladner, D. G., \& Byrn, F. W. (2009). The normal variabilities of the menstrual cycle. Fertility and Sterility, 91(2), 522-527. https://doi.org/10.1016/j.fertnstert.2007.11.073

Coneus, K., \& Spiess, C. K. (2012). Pollution exposure and child health: Evidence for infants and toddlers in Germany. Journal of Health Economics, 31(1), 180-196. https://doi.org/10.1016/j.jhealeco.2011.09.006

Cornes, R. C., van der Schrier, G., van den Besselaar, E. J. M., \& Jones, P. D. (2018). An ensemble version of the E-OBS temperature and precipitation data sets. Journal of Geophysical Research: Atmospheres, 123(17), 9391-9409. https://doi.org/10.1029/2017JD028200

Correia, S. (2014). REGHDFE: Stata module to perform linear or instrumental-variable regression absorbing any number of high-dimensional fixed effects. Boston College Department of Economics. https://ideas.repec.org/c/boc/bocode/s457874.html. Accessed 6 May 2019

Currie, J. (2009). Healthy, wealthy, and wise: Socioeconomic status, poor health in childhood, and human capital development. Journal of Economic Literature, 47(1), 87-122. https://doi. org/10.1257/jel.47.1.87

Currie, J. (2011). Inequality at birth: Some causes and consequences. American Economic Review, 101, 1-22. https://doi.org/10.1257/aer.101.3.1

Currie, J., Davis, L., Greenstone, M., \& Walker, R. (2015). Environmental health risks and housing values: Evidence from 1,600 toxic plant openings and closings. American Economic Review, 105(2), 678-709. https://doi.org/10.1257/aer.20121656

Currie, J., Graff Zivin, J., Meckel, K., Neidell, M., \& Schlenker, W. (2013). Something in the water: contaminated drinking water and infant health. Canadian Journal of Economics, 46(3), 791-810. https://doi.org/10.1111/caje.12039

Currie, J., Graff Zivin, J., Mullins, J., \& Neidell, M. (2014). What do we know about short- and longterm effects of early-life exposure to pollution? Annual Review of Resource Economics, 6(1), 217-247. https://doi.org/10.1146/annurev-resource-100913-012610

Currie, J., \& Rajani, I. (2015). Within-mother estimates of the effects of WIC on birth outcomes in New York City. Economic Inquiry, 53(4), 1691-1701. https://doi.org/10.1111/ecin.12219

Currie, J., \& Rossin-Slater, M. (2013). Weathering the storm: Hurricanes and birth outcomes. Journal of Health Economics, 32(3), 487-503. https://doi.org/10.1016/j.jhealeco.2013.01.004

Currie, J., \& Schmieder, J. F. (2009). Fetal exposures to toxic releases and infant health. American Economic Review, 99(2), 177-183. https://doi.org/10.1257/aer.99.2.177

Davenport, F., Dorélien, A., \& Grace, K. (2020). Investigating the linkages between pregnancy outcomes and climate in sub-Saharan Africa. Population and Environment, 41(4), 397-421. https:// doi.org/10.1007/s11111-020-00342-w

DeCicca, P., \& Malak, N. (2020). When good fences aren't enough: The impact of neighboring air pollution on infant health. Journal of Environmental Economics and Management, 102, 102324. https://doi.org/10.1016/j.jeem.2020.102324

Deschênes, O., Greenstone, M., \& Guryan, J. (2009). Climate change and birth weight. American Economic Review, 99(2), 211-17. https://doi.org/10.1257/aer.99.2.211

Fehring, R. J., Schneider, M., \& Raviele, K. (2006). Variability in the phases of the menstrual cycle. Journal of Obstetric, Gynecologic \& Neonatal Nursing, 35(3), 376-384. https://doi.org/ 10.1111/j.1552-6909.2006.00051.x

Figlio, D., Guryan, J., Karbownik, K., \& Roth, J. (2014). The Effects of poor neonatal health on children's cognitive development. American Economic Review, 104(12), 3921-3955. https://doi. org/10.1257/aer.104.12.3921

Fishman, R., Carrillo, P., \& Russ, J. (2019). Long-term impacts of exposure to high temperatures on human capital and economic productivity. Journal of Environmental Economics and Management, 93, 221-238. https://doi.org/10.1016/j.jeem.2018.10.001

Grace, K., Davenport, F., Hanson, H., Funk, C., \& Shukla, S. (2015). Linking climate change and health outcomes: Examining the relationship between temperature, precipitation and birth weight in Africa. Global Environmental Change, 35, 125-137. https://doi.org/10.1016/j.gloenvcha.2015.06.010

Ha, S., Liu, D., Zhu, Y., Soo Kim, S., Sherman, S., Grantz, K. L., \& Mendola, P. (2017). Ambient temperature and stillbirth: A multi-center retrospective cohort study. Environmental Health Perspectives, 125(6). https://doi.org/10.1289/EHP945

Hajdu, T., \& Hajdu, G. (2018). Smoking ban and health at birth: Evidence from Hungary. Economics \& Human Biology, 30, 37-47. https://doi.org/10.1016/j.ehb.2018.05.003

Hajdu, T., \& Hajdu, G. (2021). Post-conception heat exposure increases clinically unobserved pregnancy losses. Scientific Reports, 11(1987). https://doi.org/10.1038/s41598-021-81496-x 
Hoynes, H., Page, M., \& Stevens, A. H. (2011). Can targeted transfers improve birth outcomes?: Evidence from the introduction of the WIC program. Journal of Public Economics, 95(7-8), 813827. https://doi.org/10.1016/j.jpubeco.2010.12.006

Hu, Z., \& Li, T. (2019). Too hot to handle: The effects of high temperatures during pregnancy on adult welfare outcomes. Journal of Environmental Economics and Management, 94, 236-253. https://doi. org/10.1016/j.jeem.2019.01.006

IPCC. (2014). Climate Change 2014: Synthesis Report. Contribution of Working Groups I, II and III to the Fifth Assessment Report of the Intergovernmental Panel on Climate Change (p. 151). Geneva, Switzerland.

IPCC. (2018). Global Warming of $1.5^{\circ} \mathrm{C}$. An IPCC Special Report on the impacts of global warming of $1.5^{\circ} \mathrm{C}$ above pre-industrial levels and related global greenhouse gas emission pathways, in the context of strengthening the global response to the threat of climate change, sustainable development, and efforts to eradicate poverty. Geneva, Switzerland.

Isen, A., Rossin-Slater, M., \& Walker, R. (2017). Relationship between season of birth, temperature exposure, and later life wellbeing. Proceedings of the National Academy of Sciences, 114(51), 13447-13452. https://doi.org/10.1073/pnas.1702436114

Jarvis, G. E. (2016). Estimating limits for natural human embryo mortality. F1000Research, 5, 2083. https:// doi.org/10.12688/f1000research.9479.2

Jones, B. A. (2020). After the dust settles: The infant health impacts of dust storms. Journal of the Association of Environmental and Resource Economists, 7(6), 1005-1032. https://doi.org/10.1086/710242

Lenton, E. A., Landgren, B.-M., \& Sexton, L. (1984). Normal variation in the length of the luteal phase of the menstrual cycle: Identification of the short luteal phase. BJOG: An International Journal of Obstetrics \& Gynaecology, 91(7), 685-689. https://doi.org/10.1111/j.1471-0528.1984.tb04831.x

Li, S., Chen, G., Jaakkola, J. J. K., Williams, G., \& Guo, Y. (2018). Temporal change in the impacts of ambient temperature on preterm birth and stillbirth: Brisbane, 1994-2013. Science of The Total Environment, 634, 579-585. https://doi.org/10.1016/j.scitotenv.2018.03.385

Menclova, A. K., \& Stillman, S. (2020). Maternal stress and birth outcomes: Evidence from an unexpected earthquake swarm. Health Economics, 29(12), 1705-1720. https://doi.org/10.1002/hec.4162

Molina, O., \& Saldarriaga, V. (2017). The perils of climate change: In utero exposure to temperature variability and birth outcomes in the Andean region. Economics \& Human Biology, 24, 111-124. https:// doi.org/10.1016/j.ehb.2016.11.009

Moss, R. H., Edmonds, J. A., Hibbard, K. A., Manning, M. R., Rose, S. K., van Vuuren, D. P., et al. (2010). The next generation of scenarios for climate change research and assessment. Nature, 463(7282), 747-756. https://doi.org/10.1038/nature08823

Ngo, N. S., \& Horton, R. M. (2016). Climate change and fetal health: The impacts of exposure to extreme temperatures in New York City. Environmental Research, 144, Part A, 158-164. https://doi. org/10.1016/j.envres.2015.11.016

Nunes, M. C., Aqil, A. R., Omer, S. B., \& Madhi, S. A. (2016). The effects of influenza vaccination during pregnancy on birth outcomes: A systematic review and meta-analysis. American Journal of Perinatology, 33(11), 1104-1114. https://doi.org/10.1055/s-0036-1586101

Obradovich, N., Migliorini, R., Mednick, S. C., \& Fowler, J. H. (2017). Nighttime temperature and human sleep loss in a changing climate. Science Advances, 3(5), e1601555. https://doi.org/10.1126/ sciadv. 1601555

Pedersen, M., Giorgis-Allemand, L., Bernard, C., Aguilera, I., Andersen, A.-M.N., Ballester, F., et al. (2013). Ambient air pollution and low birthweight: a European cohort study (ESCAPE). The Lancet Respiratory Medicine, 1(9), 695-704. https://doi.org/10.1016/S2213-2600(13)70192-9

Quansah, R., Armah, F. A., Essumang, D. K., Luginaah, I., Clarke, E., Marfoh, K., et al. (2015). Association of arsenic with adverse pregnancy outcomes/infant mortality: A systematic review and metaanalysis. Environmental Health Perspectives, 123(5), 412-421. https://doi.org/10.1289/ehp.1307894

Rammah, A., Whitworth, K. W., Han, I., Chan, W., Hess, J. W., \& Symanski, E. (2019). Temperature, placental abruption and stillbirth. Environment International, 131, 105067. https://doi.org/10.1016/j. envint.2019.105067

Rangel, M. A., \& Vogl, T. S. (2019). Agricultural fires and health at birth. The Review of Economics and Statistics, 101(4), 616-630. https://doi.org/10.1162/rest_a_00806

Rasmussen, S. A., Jamieson, D. J., \& Uyeki, T. M. (2012). Effects of influenza on pregnant women and infants. American Journal of Obstetrics \& Gynecology, 207(3), S3-S8. https://doi.org/10.1016/j. ajog.2012.06.068 
Simeonova, E. (2011). Out of sight, out of mind? Natural disasters and pregnancy outcomes in the USA. CESifo Economic Studies, 57(3), 403-431. https://doi.org/10.1093/cesifo/ifr005

Stirnemann, J. J., Samson, A., Bernard, J.-P., \& Thalabard, J.-C. (2013). Day-specific probabilities of conception in fertile cycles resulting in spontaneous pregnancies. Human Reproduction, 28(4), 1110-1116. https://doi.org/10.1093/humrep/des449

Strand, L. B., Barnett, A. G., \& Tong, S. (2011). Methodological challenges when estimating the effects of season and seasonal exposures on birth outcomes. BMC Medical Research Methodology, 11(49). https://doi.org/10.1186/1471-2288-11-49

Strand, L. B., Barnett, A. G., \& Tong, S. (2012). Maternal exposure to ambient temperature and the risks of preterm birth and stillbirth in Brisbane Australia. American Journal of Epidemiology, 175(2), 99-107. https://doi.org/10.1093/aje/kwr404

Sun, S., Spangler, K. R., Weinberger, K. R., Yanosky, J. D., Braun, J. M., \& Wellenius, G. A. (2019). Ambient temperature and markers of fetal growth: a retrospective observational study of 29 million U.S. singleton births. Environmental Health Perspectives, 127(6), 067005. https://doi.org/10.1289/ EHP4648

Thrasher, B., Maurer, E. P., McKellar, C., \& Duffy, P. B. (2012). Technical Note: Bias correcting climate model simulated daily temperature extremes with quantile mapping. Hydrology and Earth System Sciences, 16(9), 3309-3314. https://doi.org/10.5194/hess-16-3309-2012

Torche, F. (2011). The effect of maternal stress on birth outcomes: Exploiting a natural experiment. Demography, 48(4), 1473-1491. https://doi.org/10.1007/s13524-011-0054-z

Trudeau, J., Conway, K. S., \& Kutinova Menclova, A. (2016). Soaking up the sun: The role of sunshine in the production of infant health. American Journal of Health Economics, 2(1), 1-40. https://doi. org/10.1162/AJHE_a_00032

Tsou, M.-W., Liu, J.-T., Hammitt, J. K., Lu, C.-H., \& Kao, S.-Y.Z. (2019). The effect of prenatal exposure to radiation on birth outcomes: Exploiting a natural experiment in Taiwan. The Japanese Economic Review. https://doi.org/10.1007/s42973-019-00016-9

Wehby, G. L., Dave, D. M., \& Kaestner, R. (2020). Effects of the minimum wage on infant health. Journal of Policy Analysis and Management, 39(2), 411-443. https://doi.org/10.1002/pam.22174

Wilcox, A. J., Harmon, Q., Doody, K., Wolf, D. P., \& Adashi, E. Y. (2020). Preimplantation loss of fertilized human ova: Estimating the unobservable. Human Reproduction, 35(4), 743-750. https://doi. org/10.1093/humrep/deaa048

Wilde, J., Apouey, B. H., \& Jung, T. (2017). The effect of ambient temperature shocks during conception and early pregnancy on later life outcomes. European Economic Review, 97, 87-107. https://doi. org/10.1016/j.euroecorev.2017.05.003

Yang, C.-Y., Chang, C.-C., Tsai, S.-S., Chuang, H.-Y., Ho, C.-K., \& Wu, T.-N. (2003). Arsenic in drinking water and adverse pregnancy outcome in an arseniasis-endemic area in northeastern Taiwan. Environmental Research, 91(1), 29-34. https://doi.org/10.1016/S0013-9351(02)00015-4

Zhang, X., Wang, Y., Chen, X., \& Zhang, X. (2020). Associations between prenatal sunshine exposure and birth outcomes in China. Science of The Total Environment, 713, 136472. https://doi. org/10.1016/j.scitotenv.2019.136472

Publisher's Note Springer Nature remains neutral with regard to jurisdictional claims in published maps and institutional affiliations. 